\title{
Competencies for 2020: Revalidation of the Curricular Competencies of the Emory University Doctor of Physical Therapy Program
}

\author{
Patricia H. Bridges ${ }^{1, *}$, Vincent M. Carter ${ }^{2}$, Tami Phillips ${ }^{3}$, Hyun Chong, Ryan Conwell ${ }^{4}$, \\ Brittany Hensley ${ }^{4}$, Alyson Kimbrell ${ }^{4}$, Mallory Sigle ${ }^{4}$ \\ ${ }^{1}$ Department of Rehabilitation Medicine, School of Medicine, Emory University, 1462 Clifton Road, Atlanta, Georgia, 30322 \\ ${ }^{2}$ Office of Institutional Research, Planning and Effectiveness, Emory University \\ ${ }^{3}$ Department of Rehabilitation Medicine, School of Medicine, Emory University \\ ${ }^{4}$ Physical Therapy students at Emory University \\ *Corresponding Author: pbridge@emory.edu
}

Copyright (C) 2013 Horizon Research Publishing All rights reserved.

\begin{abstract}
Background: Transformation in the healthcare environment prompted Emory University's Doctor of Physical Therapy Program (DPT) to revalidate its competency-based education program. The goal was to revalidate the essentialness of its curricular competencies: Provision of Patient Care, Interpersonal Relationships, Teaching and Learning, Research, Administration, and Consultation. Purpose: The purpose was to revalidate the essentialness and exhaustiveness of the curricular competencies of the Emory University DPT Program. Methods: The methods involved descriptive research, using a single observation design. Analysis of an electronic survey, comprised of forced choice and open ended questions, determined the essentialness and exhaustiveness of the competencies. The final sample consisted of 1,135 potential participants. A modified Dillman approach was used to encourage participation. Descriptive statistics were employed to analyze the frequencies for each competency. A chi-square test determined any statistically significant differences between DCE/ACCE and CCCE/CI ratings of the Administration, Research, and Consultation competencies. Results: The response rate was $56 \%$ and the majority of participants rated Provision of Patient Care (98.6\%), Interpersonal Communication (97.1\%), and Teaching and Learning (89.3\%) as essential. Administration (96.7\%), Consultation (96\%), and Research (94.2\%) were rated either essential, or useful, but not essential by most participants. Results from the chi-square test indicated statistically significant differences between DCE/ACCE and $\mathrm{CCCE} / \mathrm{CI}$ ratings of the essentialness of the Administration, Research, and Consultation competencies ( $p<0.05$ ). Discussion/Conclusions: Overall, participants rated the Emory DPT Program's curricular competencies as essential. Results suggested these competencies accurately reflect physical therapy practice expectations for the entry-level DPT graduate.
\end{abstract}

Keywords Competency-Based Education, Physical
Therapy, Clinical Education

\section{Introduction}

With new evidence and scientific knowledge coming to light every day, educators in many medical disciplines are embracing a paradigm shift from structure and process-based curricula to competency-based education.[1] At Emory University's Division of Physical Therapy, competency-based education has been practiced since 1974 . Competencies and thresholds for attaining competency were established at the foundation of the program.[2] Emory's current three-year curriculum consists of classroom lectures, laboratory experiences, clinical education rotations, and research. The programmatic model includes the three essential components of competency-based education: 1) outcome goals (overall competencies), 2) integrated instructional experiences that reflect the competencies, and 3) an evaluation instrument representative of the overall competencies.[3] Emory's competencies and related criteria are taught and evaluated didactically, and subsequently integrated and evaluated during the clinical experiences.[4]The success of Emory's competency-based program has been demonstrated by physical therapist (PT) licensure pass rates that are consistently above the national average.

\subsection{History of Competency-Based Education: Emory University School of Medicine, Department of Rehabilitation, Division of Physical Therapy}

The Division of Physical Therapy composed competency statements and related criteria when the professional program was begun in 1974.Identification and development of programmatic curricular competencies resulted from a variety of sources, including a comprehensive literature 
review; examination of the American Physical Therapy Association's (APTA) competencies, as well as those of other health professions; task analysis of physical therapy practice; suggestions from experts in competency-based physical therapy education; and faculty input. Dr. Pamela Catlin facilitated the writing of Emory's initial competencies in the Provision of Patient Care, Teaching-Learning Process, Interpersonal Relationships, Consultation, Administration, and Research.[2] After developing the overall competencies and their related component behaviors, Dr. Catlin distributed a questionnaire. She surveyed clinicians, clinical educators, and academic faculty to ensure the competencies represented the knowledge and skills necessary for entry-level physical therapy practice. In 1977, upon receipt of a Federal Title III grant awarded to Emory's Division of Allied Health Professions by the Department of Health, Education, Welfare, and Public Health, the competency statements, component behaviors, and related criteria were validated using a series of Delphi surveys. These nationwide surveys polled 140 physical therapists who were clinical instructors, both affiliated and unaffiliated with Emory, and content experts. The purpose was to obtain consensus on the following characteristics: 1) essentialness of each competency for entry-level practice, 2) essentialness of each component behavior of the related competency, 3) exhaustiveness of the component behaviors, 4) correct sequencing of the component behaviors, and 5) measurability/observability of each component behavior in the clinical setting. The return rate was $47 \%$. Essentialness was rated as follows: "essential", "useful, but not essential," or "not essential." Eighty-seven percent of the respondents rated Provision of Patient Care, Interpersonal Relationships, Teaching-Learning Process, and Consultation as essential. At least $94 \%$ of the respondents rated Administration and Research as essential; or useful, but not essential. Additionally, all component behaviors were rated essential; or useful, but not essential, by $80 \%$ of the respondents. A second nationwide Delphi survey was sent to another group of participants who had the same three classifications as the first group. The second group also validated the essentialness of the criteria of each component. Seventy-five percent of the respondents judged the criteria of each competency's component behavior to be essential, or useful, but not essential. [2]

Emory's curricular competencies were re-examined for ongoing relevancy in 1985 by surveying Emory clinical educators, and also educators who were members of the Education section of the American Physical Therapy Association. The following competencies were rated essential by respondents: Provision of Patient Care (100\%), Interpersonal Relationships (98\%), Teaching-Learning Process $(89 \%)$ and Consultation (90\%). Administration and Research were reported to be either essential; or useful, but not essential, by $100 \%$ of the respondents. Additionally, the component behaviors were confirmed to be exhaustive, representative, sequenced correctly, and measurable and observable in the clinical setting. No programmatic revisions were made, as findings suggested the competencies transcended changes in PT entry-level education, as well as, the manner and pattern of healthcare.[5]

\subsection{Changes in the Healthcare Environment: Effects on Physical Therapy Practice}

A major goal of any physical therapy education program is to prepare the graduates for a designated role in healthcare. As with other professional healthcare educational programs, physical therapy is continuously evolving to meet changes in the healthcare environment and the needs of society.[6] Myriad changes in the healthcare environment have occurred since the last revalidation of the competencies including: patient care models, organizational management, cost containment, evolving direct access, insurance reimbursement, productivity standards, an increasing elderly population, advances in medical technology and treatments, and an increasing interest in health promotion.[7]

As physical therapists (PTs) have responded to these changes, their roles and responsibilities have evolved.[5] The APTA described this in the Vision 2020 document, which states that by 2020 PT will be "provided by PTs who are doctors of physical therapy, recognized by consumers and other healthcare professionals as the practitioners of choice to whom consumers have direct access for the diagnosis of, interventions for, and prevention of impairments, activity limitations, participation restrictions, and environmental barriers related to movement, function, and health."[8] Using the World Health Organization's Model of Health, PTs address impairments, limitations, and restrictions, so that individuals can return to functional activities and participate in their work, family, and extracurricular activities. Therefore, PT is a profession requiring continuous adaption to ensure successful patient outcomes.

Education programs should periodically reassess and revalidate their curricular competencies' essentialness for current and future PT practice.[9] The purpose of this study was to reevaluate Emory's curricular competencies for an entry-level doctor of physical therapy graduate by addressing the following questions:

1. Are the curricular competencies of Emory University's Division of Physical Therapy essential for the entry-level physical therapist?

2. Are all competencies essential for practice fully represented?

3. Are there differences between Directors of Clinical Education (DCEs)/Academic Coordinators of Clinical Education (ACCEs), and Center Coordinators of Clinical Education (CCCEs)/Clinical Instructors (CIs) as it pertains to the ratings of the essentialness of the competencies? 


\section{Review of Literature}

\subsection{Competency-Based Education Practice and Methods}

Competency-based education has been identified as an effective educational strategy for developing practitioners of the health professions.[4,5,10] Emphasis is placed on learning to apply knowledge and skills in clinical practice rather than memorizing facts. Students are evaluated according to the defined competencies and must successfully demonstrate proficiency.[11] Formative evaluation is provided to the student throughout the learning experience. The purpose being not to grade the student, but rather to help the learner focus on the particular learning necessary for mastery of each behavior in the competency. The formative evaluation describes what has been mastered and increases awareness of what skills still need to be developed.[12] The evaluation includes the steps needed to achieve mastery. The progressive development of mastery, as well as the repeated evidence of mastery, serves as a very powerful reinforcement for student learning.[13]This differs from norm-referenced curricula, which "distributes achievement across a continuum and identifies precisely different levels of achievement along that continuum.[14] A physical therapy program using a competency-based model defines a set of overall competencies based on the needs of society, patient needs, education of the professional, and the role of the professional. Ultimately, teaching strategies are developed so that the competencies are integrated across both the didactic and clinical segments of the curriculum. $[4,10]$

\subsection{An Evolving Healthcare Environment}

The healthcare system is constantly evolving. These changes drive the profession to participate in the national health agenda; respond to the societal need for accessible, affordable, and effective healthcare; and shape the future of physical therapy practice beyond 2020 . Over the last two decades, there has been an intentional move, in most states, to allow patients direct access to a PT. While policy on this issue continues to develop, DPTs need to be trained to diagnose various conditions, and possess the evaluation and treatment skills necessary to manage musculoskeletal and neurological conditions in a direct access setting.[15] PT educational institutions should prepare new graduates to practice at their maximal potential in both the current and future healthcare systems, which requires on-going reevaluation and curricular revisions to ensure the didactic and clinical curricula are representative of the knowledge and skills essential for practice.[16] PTs must be responsive to other healthcare changes including new models for patient care, management organization, cost containment, and productivity standards.[17]

\section{Methods}

\subsection{Respondents}

This study was reviewed by the Emory University Institutional Review Board (IRB) and determined to not need IRB approval. Potential respondents were chosen due to their knowledge and expertise in the area of clinical education, and grouped by job responsibility for analysis purposes. Three classifications were developed and consisted of Directors of Clinical Education (DCEs)/Academic Coordinators of Clinical Education (ACCEs), Center Coordinators of Clinical Education (CCCEs), and Clinical Instructors (CIs). The Division of Physical Therapy at Emory University made available their CI and CCCE database, and the APTA's Director of the Department of Academic/Clinical Education Affairs provided a list of DCEs/ACCEs. A census population of 1,305 was obtained. An analysis determined that 587 respondents were needed for a $+/-3 \%$ margin of error at a $95 \%$ confidence level. Results from a previous validation study yielded a $58 \%$ response rate.[5] As a result; the sample size of 587 was adjusted to 1,135 . The final sample consisted of DCEs $(n=241)$ and CCCEs $(n=304)$ from the census population that had good contact information, and a sample of CIs $(n=590)$ based on their proportion in the census population.

\subsection{Questionnaire}

An electronic survey, comprised of both forced choice/closed-ended and open-ended questions, was developed to measure the essentialness of the Emory DPT Program's overall competencies and component behaviors. The survey consisted of 3 sections. The first outlined the overall competencies of the Emory DPT program. Respondents were asked to evaluate the following competencies: Provision of Patient Care, Interpersonal Communications, Teaching-Learning Process, Administration, Research, and Consultation. Essentialness was rated by selecting one of the following responses: a) essential, b) useful, but not essential, or c) not essential. The following operational definitions were used:

a)Essential: the knowledge and skills are necessary for the acceptable practice of PT by an individual entering the profession

b)Useful, but not essential: the knowledge and skills are helpful, but not necessary for the acceptable practice of PT by an entry-level therapist

c)Not essential: the knowledge and skills are neither helpful nor necessary to entry-level PT practice

Exhaustiveness of the competencies was denoted by answering "yes" or "no" to the following questions: "Are the six competencies above a complete list of all competencies that should be required of the entry-level physical therapist?" If the respondent selected no, they were asked to list additional competencies that should be added.

The second section presented the component behaviors of four competencies: Provision of Patient Care, Interpersonal 
Communications, Teaching-Learning Process, and Administration. Respondents were asked to rate each component behavior for essentialness. Then, the exhaustiveness of the behavior components for a particular competency was addressed by asking, "Are the behaviors above a complete list of all behaviors that should be included in the competency?" An additional question was asked about the measurability and/or observability of the component behaviors, with respondents answering "yes" or "no" to the following statement: "Are the behaviors and accompanying criteria in the competency observable and/or measurable?" If "no", the respondent was directed to identify those behaviors. Finally, respondents were asked: "Are there any behaviors listed above in the competency that should not be included?" If the respondent selected yes, they were asked to list the behaviors that should not be included.

The third section of the survey consisted of 14 demographic questions regarding the experience and educational backgrounds of the respondents. For example, the demographic questions asked respondents to name their discipline, entry-level degree, highest earned degree, state of residence, practice facility, gender, years as a clinician, and years supervising students.

\subsection{Survey Methods}

Before the survey was distributed, a test-retest reliability analysis was conducted to establish the survey's reliability. Eighteen PTs were asked to participate and twelve useable responses were returned. Respondents were given a two-day deadline upon receipt of the survey. Ten days later, responding participants were sent the same survey for completion. Reliability of the respondents' ratings regarding essentialness of the six competencies was determined by measuring the differences between the two administrations, and also the percentage agreement of cases on which raters gave identical ratings.

Following the test-retest analysis, a modified Dillman approach was used to administer the survey to a sample of 1,135 DCEs/ACCEs, CCCEs, and CIs.[18]A pre-notification email was sent to the entire sample informing them of their random selection. They were also offered a chance to be included in a random drawing for an iPad. Three days later, respondents received the electronic survey with detailed instructions and definitions of the content items. Non-respondents were sent a reminder email once per week for four weeks, and reminder phone calls were made one week after the final reminder email.

\section{Results}

Results of the test-retest analysis show there were no statistically significant differences in ratings between the two administrations. Respondents had greater than 70 percent agreement on the ratings of all the competencies, with the exception of Consultation, in which their agreement was $50 \%$.(Table 1)

SPSS was used to analyze the final survey results. The total number of respondents was $n=637$. Frequency distributions were calculated for each competency. The majority of respondents rated Provision of Patient Care (98.6\%), Interpersonal Communications (97.1\%), and the Teaching-Learning Process $(89.3 \%)$ as essential. While there was less agreement with regard to the Administration, Research, and Consultation competencies, the majority of respondents rated each competency as either essential or useful, but not essential. For example, more than half of the respondents reported Administration (56.2\%) and Consultation (53.1\%) as essential; while slightly less than half rated the Research competency as essential (42.6\%). Similarly, slightly less than half of respondents rated Administration and Consultation as useful, but not essential, at $40.5 \%$ and $42.9 \%$ respectively, while slightly more than half $(51.6 \%)$ rated the Research competency useful, but not essential. (Figure 1) The proportion of respondents rating any competency as not essential was less than $6 \%$ : Provision of Patient Care $(0.8 \%)$, Interpersonal Communications $(0.8 \%)$, Teaching-Learning Process (1.3\%), Administration (3\%), Research (5.9\%), and Consultation (3.2\%).

Table 1. Test-Retest Reliability of Participant Rating of the Essentialness of the Six Competencies

\begin{tabular}{|c|c|c|c|c|c|c|c|c|c|c|c|c|c|}
\hline & & \multicolumn{2}{|c|}{$\begin{array}{l}\text { Provision of } \\
\text { Patient Care }\end{array}$} & \multicolumn{2}{|c|}{$\begin{array}{c}\text { Interpersonal } \\
\text { Communications }\end{array}$} & \multicolumn{2}{|c|}{$\begin{array}{c}\text { Teaching-Learning } \\
\text { Process }\end{array}$} & \multicolumn{2}{|c|}{$\begin{array}{l}\text { Administrative } \\
\text { Process }\end{array}$} & \multicolumn{2}{|c|}{ Research } & \multicolumn{2}{|c|}{ Consultation } \\
\hline & & $\mathrm{T} 1$ & $\mathrm{~T} 2$ & $\mathrm{~T} 1$ & $\mathrm{~T} 2$ & $\mathrm{~T} 1$ & $\mathrm{~T} 2$ & $\mathrm{~T} 1$ & $\mathrm{~T} 2$ & $\mathrm{~T} 1$ & $\mathrm{~T} 2$ & $\mathrm{~T} 1$ & $\mathrm{~T} 2$ \\
\hline \multirow{4}{*}{$\begin{array}{c}\text { Wilcoxon } \\
\text { Signed } \\
\text { Ranks Test }\end{array}$} & Median & 3.00 & 3.00 & 3.00 & 3.00 & 3.00 & 3.00 & 3.00 & 2.00 & 2.00 & 2.00 & 2.00 & 2.00 \\
\hline & & \multirow{2}{*}{\multicolumn{2}{|c|}{.000}} & \multirow{2}{*}{\multicolumn{2}{|c|}{-1.000}} & \multirow{2}{*}{\multicolumn{2}{|c|}{-1.414}} & \multirow{2}{*}{\multicolumn{2}{|c|}{-1.732}} & \multirow{2}{*}{\multicolumn{2}{|c|}{-.577}} & \multirow{2}{*}{\multicolumn{2}{|c|}{-.816}} \\
\hline & Z & & & & & & & & & & & & \\
\hline & $\mathrm{p}$ & \multicolumn{2}{|c|}{1.000} & \multicolumn{2}{|c|}{.317} & \multicolumn{2}{|l|}{.157} & \multicolumn{2}{|c|}{.083} & \multicolumn{2}{|c|}{.564} & \multicolumn{2}{|c|}{.414} \\
\hline $\begin{array}{c}\text { Percent } \\
\text { Agreement }\end{array}$ & & \multicolumn{2}{|c|}{$100 \%$} & \multicolumn{2}{|c|}{$92 \%$} & \multicolumn{2}{|l|}{$85 \%$} & \multicolumn{2}{|c|}{$77 \%$} & \multicolumn{2}{|c|}{$77 \%$} & \multicolumn{2}{|c|}{$50 \%$} \\
\hline
\end{tabular}


Table 2. Essentialness of the six competencies as rated by DCE/ACCEs and CCCE/CIs

\begin{tabular}{|c|c|c|c|}
\hline \multirow{3}{*}{ Competency } & \multicolumn{2}{|c|}{ Job Responsibility } & \multirow{3}{*}{$?]_{2}$} \\
\hline & $\mathrm{DCE} / \mathrm{ACCE}$ & $\mathrm{CCCE} / \mathrm{CI}$ & \\
\hline & $(n=120)$ & $(\mathrm{n}=513)$ & \\
\hline Provision of Patient Care & 119 & 505 & .366 \\
\hline Interpersonal Communications & 118 & 494 & 2.150 \\
\hline Teaching-Learning Process & 112 & 455 & 2.528 \\
\hline Administrative Process & 93 & 263 & $27.194 *$ \\
\hline Research & 72 & 197 & $18.422 *$ \\
\hline Consultation & 79 & 259 & $9.205^{*}$ \\
\hline$* p<.05$ & & & \\
\hline
\end{tabular}

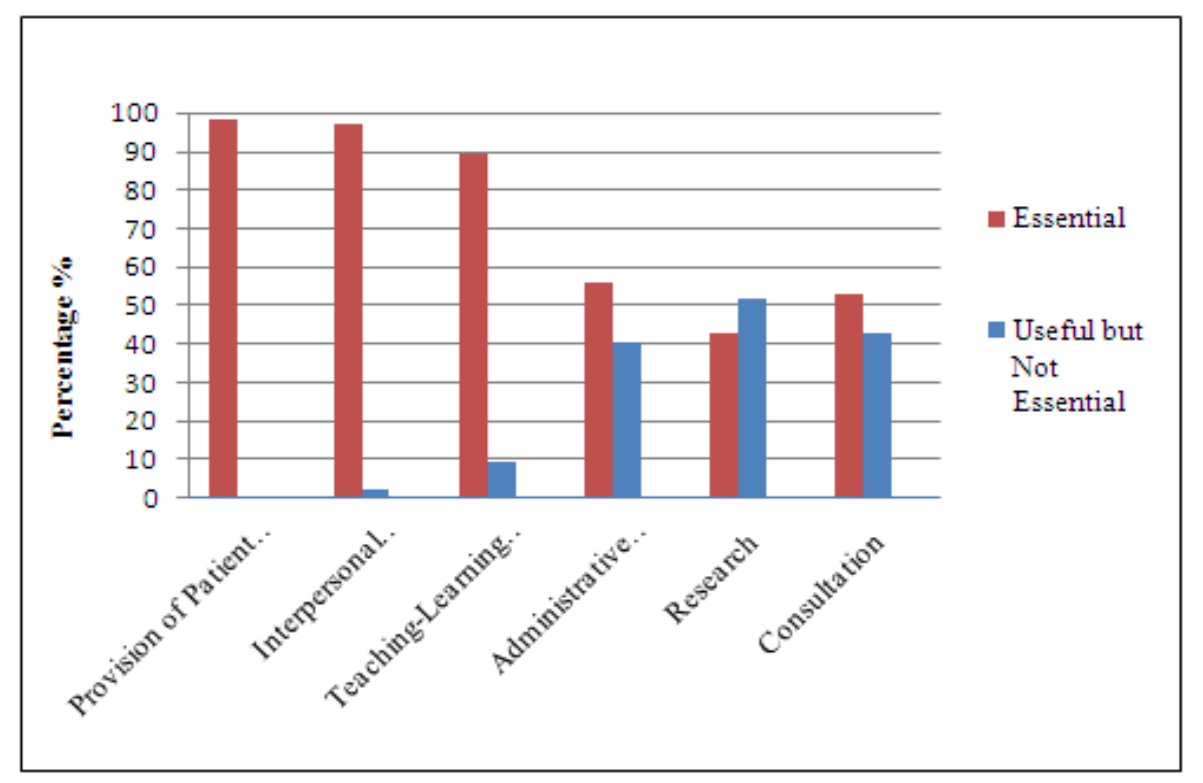

Figure 1. Overall Ratings of the Essentialness of the Competencies

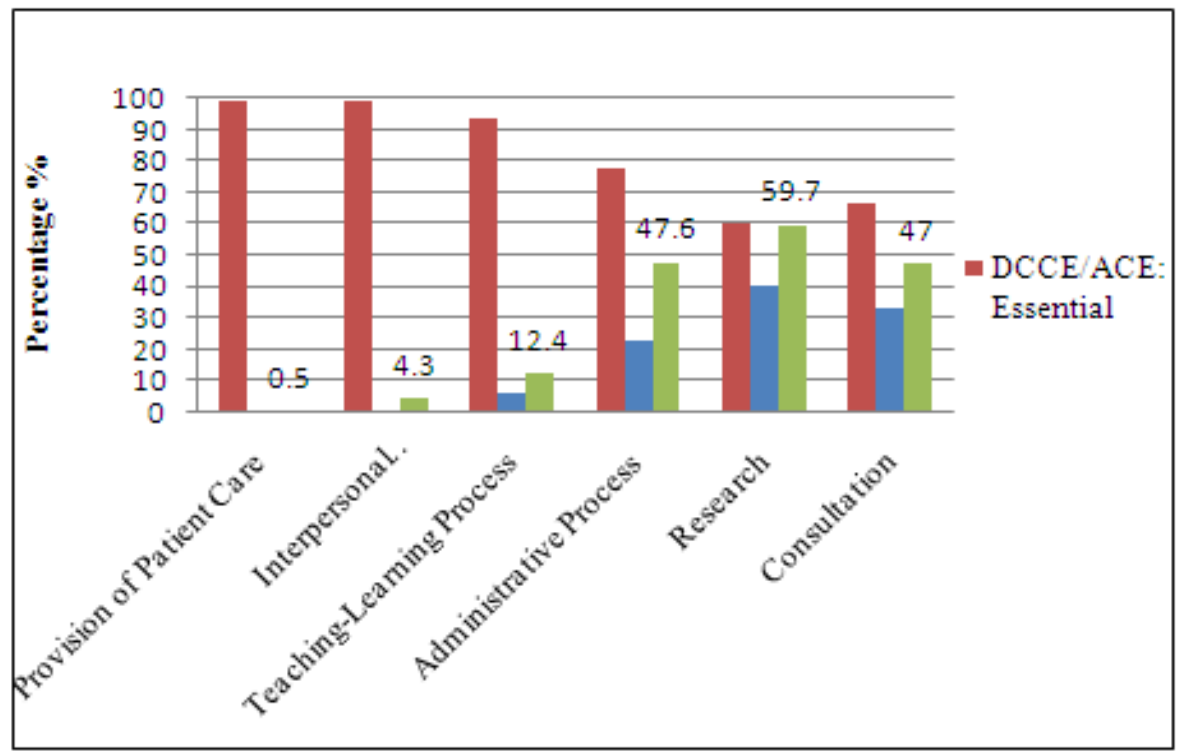

Figure 2. DCE/ACCE Ratings of the Essentialness of the Competencies $(n=120)$ 


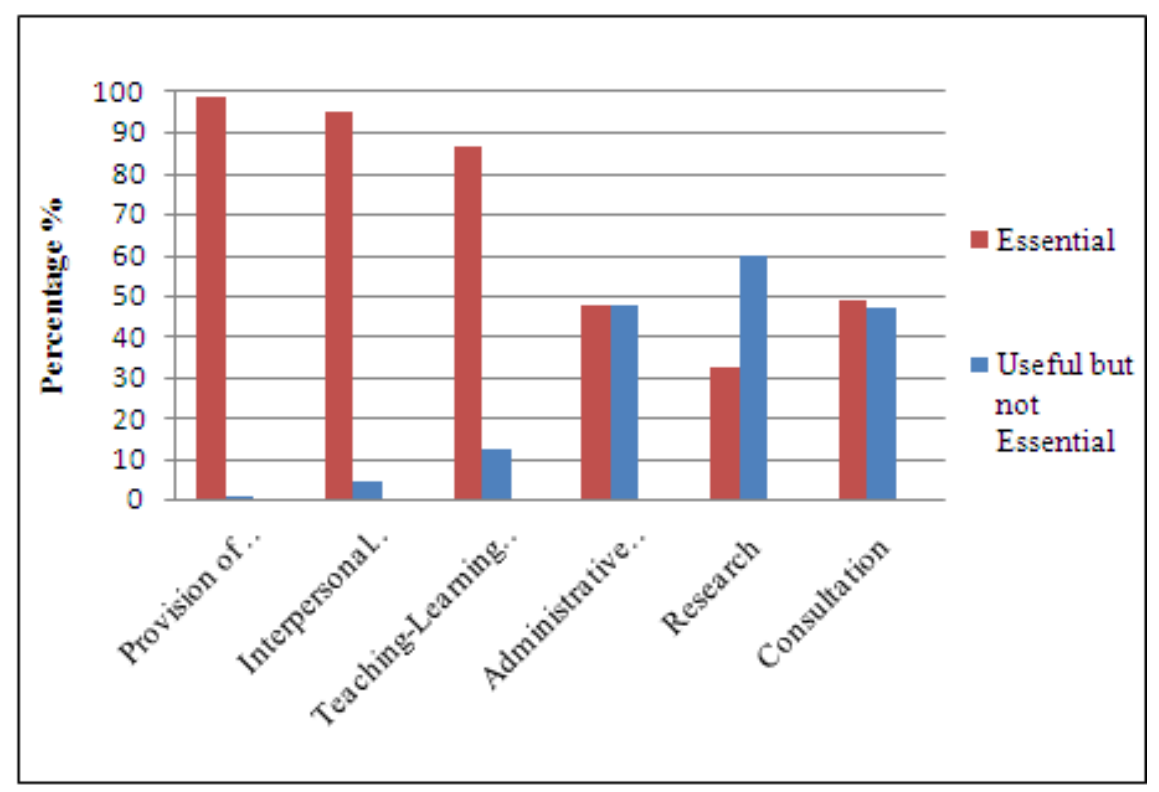

Figure 3. CCCE Ratings of the Essentialness of the Competencies $(n=186)$

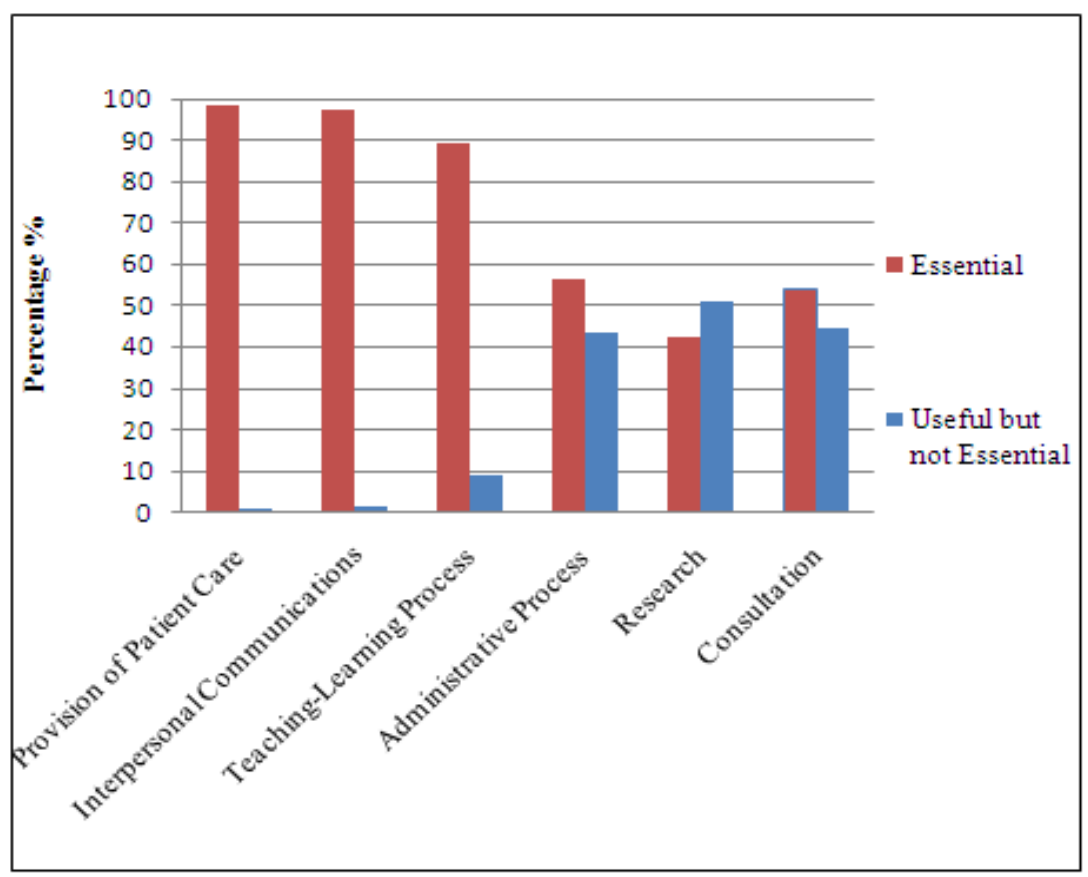

Figure 4. CI Ratings of the Essentialness of the Competencies $(n=329)$

The differences found with respect to the Administration, Research, and Consultation competencies prompted a closer look at those ratings. Crosstabs revealed that the greatest differences were between DCE/ACCEs and CCCEs/CIs. (Figures 2-4) Furthermore, results from chi-square tests indicated these differences were statistically significant at a .05 alpha level. For example, a higher percentage of DCE/ACCEs rated Administration as essential (77.5\%) compared to CCCEs (47.6\%) and CIs (53.4\%). The majority of DCE/ACCEs also rated Research essential (60\%); whereas the majority of CCCEs and CIs reported this competency as useful, but not essential $(59.7 \%$ and $51.2 \%$, respectively).Likewise, Consultation was rated as essential by the majority of DCE/ACCEs (66.4\%), with considerably fewer CCCEs $(48.6 \%)$ and CIs $(42.3 \%)$ reporting the same rating. The results of chi-square tests indicate that the differences between DCE/ACCE and $\mathrm{CCCE} / \mathrm{CI}$ ratings of Administration, Research, and Consultation were significantly larger than what would be expected by chance. (Table 2)

Survey respondents were also asked "Are the six competencies above a complete list of all competencies that 
should be required of the entry-level physical therapist?" The results indicate that 522 responded "yes", while 95 responded "no" and 20 had no response. (Figure 5)

Data for the question, "Are the six competencies above a complete list of all competencies that should be required of the entry-level PT", was also analyzed by job responsibility of the respondents: DCE/ACCEs, CCCEs, and CIs. The majority of CCCEs and CIs ( $86.3 \%$ and $89.7 \%$, respectively) reported the six competencies were exhaustive. In contrast, only $67.5 \%$ of DCE/ACCEs felt that no other competencies should be added to the list. (Figure 6) Upon further examination, the greatest differences were found between DCE/ACCEs and CCCEs/CIs. Chi square results revealed that these differences were indeed statistically significant. (Figure 6) Respondents reporting the six core competencies as not exhaustive were given an opportunity to write in any suggested additions. The following were the most common themes from the qualitative data: professionalism, inter-professional relationships, clinical documentation, cultural competence or cultural sensitivity, problem solving or critical thinking, and safety.

Specific components from the demographics section were analyzed in Figure 7 to display the representation of survey respondents: highest degree earned, year graduated with entry-level degree, job responsibilities greater than $50 \%$ of the time, and sex. (Figure 7) The majority of respondents reported a Baccalaureate Degree (31.9\%) as their highest degree earned, followed by Professional Masters (28.7\%) and Professional Doctorate (24.6\%). Over half of respondents reported entry-level degree graduation after the year 2000 (50.7\%). A smaller percentage (37.4\%) reported graduating within years 1991-2000. The majority stated their role in clinical education was as a CI (61.1\%); $25.4 \%$ reported CCCE/CI. There were significantly more females
$(78.9 \%)$ than males $(21.1 \%)$. This demographic information demonstrates the diversity represented in the population surveyed for this study.

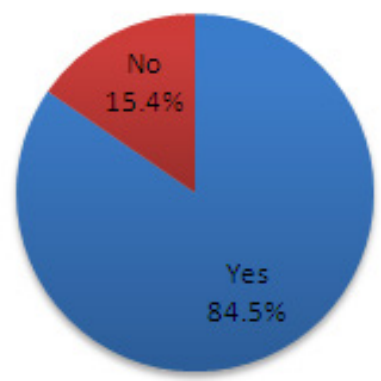

Figure 5. Are the six competencies above a complete list of all competencies that should be required of the entry level physical therapist? $(\mathrm{n}=617)$

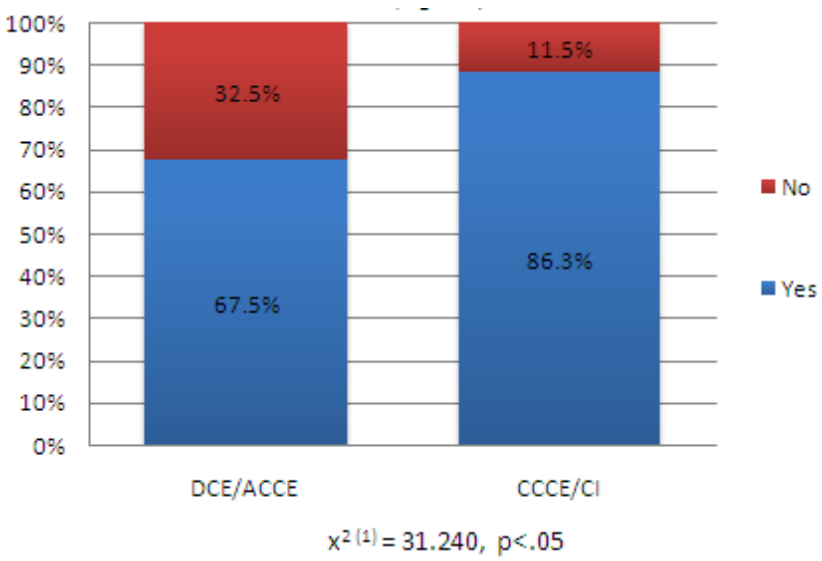

Figure 6. Are the six competencies above a complete list of all competencies that should be required of the entry level physical therapist? (n $=617$ )

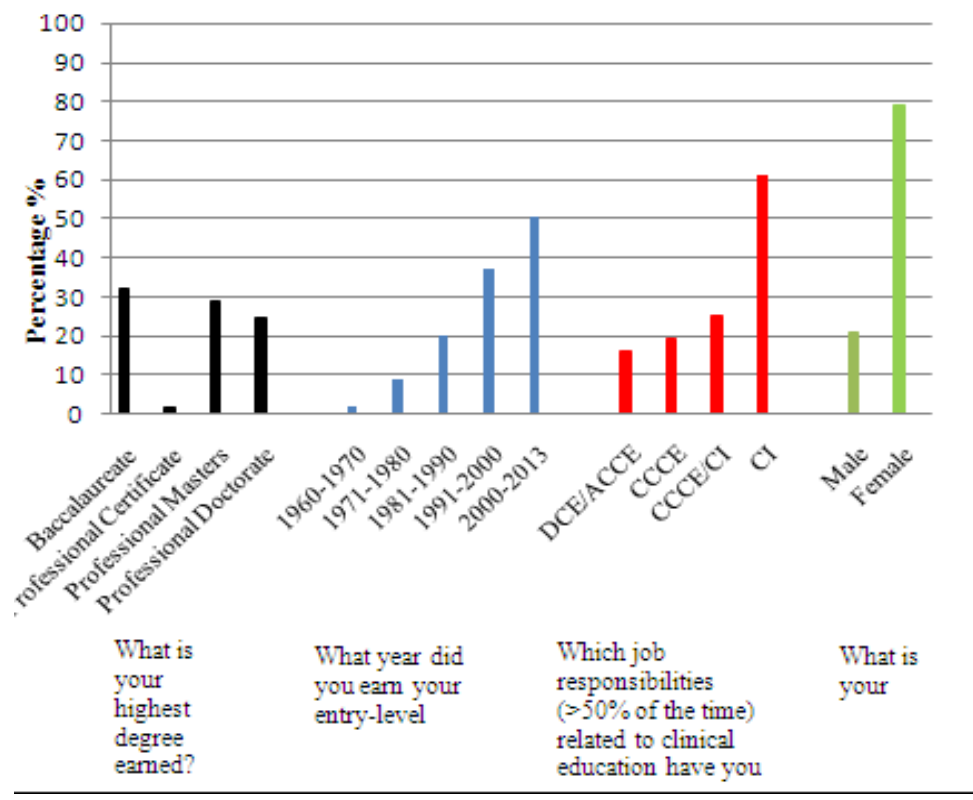

Figure 7. Demographic Distribution of Survey Respondents (Education, Graduation Year, Job Responsibilities, Sex) $(n=637)$ 


\section{Discussion}

The results of this study confirm the continued relevance of Emory's DPT curricular competencies. The majority of respondents rated the overall competencies (Provision of Patient Care, Interpersonal Communications, Teaching-Learning Process, Administration, Research, and Consultation) essential, or useful, but not essential for a DPT entry-level graduate. The findings are not surprising, considering the functions of an entry-level DPT and the validation of these competencies in previous studies.[4,5]

\subsection{Provision of Patient Care}

The majority of respondents rated Provision of Patient Care, the evaluation and treatment of clients/patients and all this process encompasses, as an essential competency in entry-level PT practice. This is not surprising given that patient care is the central function of a PT. According to the APTA, the physical therapist "examines [patients/clients] and develops a plan of care that promotes the ability to move, reduces pain, restores function, and prevents disability".[19]In addition to "therapeutic exercise and functional training [which] are the cornerstones of [PT] treatment" other modalities and techniques may be used as well.[19]The APTA also describes the PT's role in their article, Today's Physical Therapist: A comprehensive review of a $21^{\text {st }}$ century healthcare professional.[20] They state, "physical therapists are healthcare professionals who maintain, restore, and improve movement, activity, and health enabling an individual to have optimal functioning and quality of life, while ensuring patient safety and applying evidence to provide efficient and effective care."[21] The APTA also acknowledges that PTs "evaluate, diagnose, and manage individuals of all ages who have impairments, activity limitations, and participation restrictions" as well as promote "health, wellness, and fitness through risk factor identification and the implementation of services to reduce risk, slow the progression of or prevent functional decline and disability, and enhance participation in chosen life situations".[20]One large component of the Provision of Patient Care is critical thinking and problem solving skills; skills required in order to use the results of the examination to determine a diagnosis and create an individualized plan of care for the patient.[22,23] Several studies report that new graduates are expected by their employers and patients to function independently, handle complex cases, and justify their clinical decisions with scientific evidence.[16,22,23] All of these behaviors are essential to performing the roles and responsibilities of a PT, and thus the Provision of Patient Care competency is essential for PT practice.

\subsection{Interpersonal Communications}

Interpersonal Communications was rated as essential by $97.1 \%$ of the CIs, CCCEs and DCEs. This is somewhat expected given the critical influence patient and professional interactions have on patient outcomes.[24]The findings are supported by Englander et al. in their development of a robust list of physician competencies which could be used by any healthcare profession. Interpersonal and Communications Skills, operationally defined as "demonstrating interpersonal and communication skills that result in effective exchange of information and collaboration with patients, their families and health professionals," was one of eight core competencies defining the desired outcome at the end of physician training.[25]

Interpersonal Communications includes communication and relations between the physical therapist and the patient, and potentially the patient's family or caregivers. Patients reported in a study by Beattie that the most important issues when receiving medical care included being treated with respect and being involved in treatment decisions. Both can be achieved through positive interpersonal communication between the healthcare professional and the patient. Research has shown that patient satisfaction is vital in the physical therapy setting,[16,26,27] and that patient satisfaction with physical therapy treatment is not only based on physical improvements in one's condition, but more importantly on overall care and treatment throughout the process.[29,30,31]

\subsection{The Teaching-Learning Process}

Results indicate that respondents believe Teaching-Learning is an essential PT competency to master. Literature also supports this essential skill. Patient education occurs frequently during PT services; 80\%-100\% of therapists reported they provide patient education as part of their session.[32] Physical therapists can also actively involve the patient in the plan of care by incorporating teaching and learning principles. "Gaining participation [of the patient] takes effort and skill on the part of the [PT].'"[32]A study by May revealed a great need for more PT programs to include the Teaching-Learning Process in their curriculum. May states that even though " $99 \%$ of [PTs] believed teaching is an important skill in their practice, only $34 \%$ reported they had received instruction in teaching" during PT school.[23]The literature, as well as the results of this study, supports the Teaching-Learning Process as a core competency, essential to PT practice.

\subsection{Administration}

The majority of respondents $(56.2 \%)$ rated the Administration competency as essential to PT practice. Evidence suggests Administration is one of the components that "forms the foundation for the organization and operation of clinical services, reimbursement for services, and the potential growth and development of new [PT] services".[33] In today's healthcare environment, it is difficult for any clinician to manage the care of patients without considering a facility's resources, reimbursement services, and numerous other factors related to the operation of clinical 
practice.[16,34,35] A national survey of APTA members reported new graduates are expected to be moderately independent in performing administration and management skills in the following areas: information management, leading and directing, quality/risk management, practice analysis, personnel management, skills, operational analysis, and operational management skill.[16,34] This is consistent with the Administration competency in the Emory DPT curriculum.

The results of both the national study and the current study support the continued use of the Administration competency. It is noteworthy that a substantial proportion of respondents $(40.8 \%)$ rated this competency useful, but not essential. This rating could potentially be due to current changes in the healthcare environment such as increased clinical workload and paperwork, along with diminishing resources and time. These factors are potential sources of stress that could adversely impact practice and the delivery of PT services.[34,35]

\subsection{Research}

Respondents (51.6\%) reported Research as a useful, but not essential competency. Emory University's DPT Program requires students to demonstrate competency in Research. This involves using a problem-solving process to perform research, as well as using critical analysis to understand and apply concepts and findings generated by self and others in the literature.[2]

Physical therapy organizations, including the APTA, have acknowledged evidence-based practice (EBP) as a priority of PT practice. Current literature strongly supports the use of scientific evidence for clinical decision-making.[36] Utilizing EBP provides a sound method for making clinical decisions and bridges the gap between knowledge and clinical practice.[37] Mather reports that evidence-based PT has become more feasible with an enormous increase in the volume and accessibility of high-quality clinical research in recent years.[38]Despite this, many PTs do not recognize research as essential; they also do not translate research to include EBP. Some hypotheses for this include current health policies, the complexity of PT practice, incomplete access to the evidence, difficulty interpreting evidence, organizational barriers, and ineffective continuing education courses. Another barrier is time constraints.[38] Schreiber et al. found that "Time constraints are almost universally a barrier. Clinicians refer to the pressures of today's healthcare environment and administrator's emphasis on productivity as factors that directly inhibit their ability to seek out, gather, read, and integrate scientific information relevant to daily practice."'[36]

The open-ended questions in the survey provided more insight into the respondents' thoughts about the Research competency. Many commented that if the Research competency included the use of EBP and the clinical application of research, they would agree it was a core competency. However, if it only included research skills and the ability to perform research, it was not an essential competency. This repetitive theme is one explanation for a lower rating of essential for this competency compared to the other five competencies evaluated. This correlates with recent research on EBP in the PT setting. Schreiber et al. reported most PTs do not find the use of research essential and have a tendency to base practice decisions on anecdotal evidence, and utilized treatment techniques, with little scientific evidence to support their use.[36] Studies from 1997-1999 showed that PTs demonstrated a strong tendency to rely on initial education and training when selecting treatment techniques for patients instead of utilizing current evidence to guide their decisions.[36]

The Research process was designed to instruct students in the process of critically reviewing the literature and thereby fostering development of a competent consumer of research evidence. Furthermore, it serves as a guide for using the research process to answer questions generated by oneself. The implementation of the research process in the DPT program is similar to a study conducted by Green et al.[39] An evidence-based medicine (EBM) curriculum was employed with the goal to increase residents' decision-making, evaluation, and application of evidence from the medical literature. Students participated in a pre-test on EBM prior to the curriculum. After participating in the curriculum for one year, significant results were found showing increased scores on post-tests. It was found that an EBM curriculum based on adult learning theory was found to improve residents' EBM skills and behaviors.[39]While the majority of respondents did not report the Research competency as essential, the literature supports the use of EBP to guide PT treatment in order to provide optimal patient care.

\subsection{Consultation}

Consultation was defined as an essential competency by the majority of survey respondents $(53.1 \%)$. This is consistent with current research suggesting that the ability to work with professionals from other disciplines in order to deliver collaborative, patient-centered care is a critical element of professional practice.[40] Various behaviors have been identified in the literature as essential for Consultation: communication; understanding other health professionals' roles; effective team working skills; conflict resolution; the ability to contribute to shared care plans and goal setting; a willingness to collaborate; and mutual trust and respect.[16,40] Dean et al. described the progressive shift occurring in the healthcare environment from treating the symptoms of an acute illness or condition, to managing the patient's lifestyle, treating chronic conditions, and focusing on prevention. This requires health professionals to approach their patients' conditions in a comprehensive manner, and consult others when appropriate to deliver the best, well-rounded care to their patients.[41]This collaboration includes the patient, and the family or caregivers; moreover, the literature supports that this should occur in an 
environment of mutual trust and respect.[40] One key objective of Emory University is that students will be encouraged to consult with other healthcare professionals for the purpose of providing comprehensive care. This supports the response of the majority of respondents that Consultation is an essential competency.

\subsection{Suggested Competencies}

In addition to rating the essentialness of Emory's overall DPT curricular competencies, respondents were also asked if they thought any other competencies should be added. The following were the most common themes suggested by respondents: professionalism, inter-professional relationships, clinical documentation, cultural competence or cultural sensitivity, problem solving or critical thinking, and safety. Thirty-four respondents suggested professionalism and similar attributes as a core competency. Currently, professionalism is listed within the Administration competency as a component behavior. However, respondents may feel it should stand alone as its own competency due to its importance in clinical care. Given the format of the Emory evaluation form where professionalism is pulled out and listed as the first item on the evaluation form its importance may be self-evident. Eleven respondents reported cultural competency and/or cultural sensitivity should be a core competency. Although Emory emphasizes cultural competence/sensitivity throughout the program, it is not specifically listed as a competency or behavioral component and should be discussed further during curricular evaluations. Nine respondents reported clinical documentation and eight respondents reported problem solving/critical thinking and/or clinical reasoning should be core competencies; both are currently component behaviors of Provision of Patient Care. Five respondents reported safety and another five suggested evidence-based practice (EBP) should each be considered a core competency. Safety and EBP are component behaviors of the Provision of Patient Care competency. Several individuals that listed EBP, also noted that if the Research competency included evidence-based practice this addition would not be needed. By suggesting competencies already included in Emory's curriculum as component behaviors, respondents may have been suggesting these skills be developed as individual competencies because of their essentialness to practice. It is also possible they were suggested because respondents did not understand what component behaviors and skills were included within each existing competency.

\subsection{Conclusion}

Results support the use of Emory University's DPT curricular competencies. Provision of Patient Care, Interpersonal Communications, and the Teaching-Learning Process were reported essential by the majority of respondents, validating their necessity. Greater than $90 \%$ of respondents rated Administration, Research, and
Consultation either essential, or useful but not essential; with roughly a 50-50 split between ratings of essential, and useful but not essential on each competency. These findings suggest that all six competencies have been validated as important for entry-level physical therapists. Furthermore, the competencies continue to transcend changes in physical therapy entry-level practice and the manner and pattern of healthcare delivery. In other words, the competencies continue to be relevant despite the changes in PT practice and the movement to an entry-level doctorate, supporting their current and future use in Emory's DPT curriculum. The findings also suggest that the competencies are exhaustive of the competencies needed by an enrtry-level PT. An analysis of respondents' suggestions for additional competencies revealed that most of the suggestions were already incorporated into the exiting six competencies. Although results cannot be generalized to all populations, Emory's core curricular competencies and behaviors can serve as a model to develop competent entry-level PTs.Future reports of the findings of this survey should discuss the component behaviors of the competencies, which are used to evaluate the students in the clinical setting. Additional studies are needed to ensure course objectives match the competencies, component behaviors, and criteria.

\section{Limitations}

Several limitations were identified, including the inability to generalize the results to all physical therapists education programs. One limitation was the potential misinterpretation of some of the survey questions by some of the respondents. If respondents did not understand the questions, or had personal biases, the ratings could be affected. This limitation was discovered in some participants' responses to open-ended questions. For example, a few respondents reported being unsure if the competencies suggested in the open-ended section were included elsewhere within another competency. Other respondents stated they could not suggest any additional competencies because they were unclear what the current competencies included. One respondent wrote, "It is not clear what each of these 6 topics includes. So it is difficult to answer the [open-ended] question above". Another reported she "would need to know what behaviors and criteria would be listed under each competency" in order to write in any additional ones. And finally, "Your request to assess the relative essentialness to the above categories is problematic. When viewing the details, some items are essential and some are not in my opinion. How should we make our decision to rate the entire category?" Such comments reveal that some of the questions could have been misinterpreted by some of the respondents. To the extent that such misinterpretations occurred, this could explain why some respondents' ratings of Administration, Research, and Consultation were split between essential and useful, but not essential. Finally, the survey results may have limited generalizability. Considering that all CIs and CCCEs 
surveyed in this study currently have affiliations with Emory University's DPT Program, the data obtained from these individuals cannot be generalized to all PT programs. Conversely, the data obtained from DCE/ACCEs can be generalized to other populations, as these individuals have no affiliation with Emory and were chosen from a sample obtained from the APTA. The DCE/ACCEs' data can provide beneficial information to other PT schools as they develop and/or revalidate their curricula.

\section{REFERENCES}

[1] Carraccio C, WolfsthalSD, Englander R, Ferentz K, Martin C. Shifting paradigms: From Flexner to competencies. Acad med.2002:77;361-367.

[2] Catlin P, Barrett S, Binder-Macleod S et al. Competencies and criteria for the entry-level physical therapist. Division of Physical Therapy, Emory University School of Medicine. 1983

[3] Spady WG. The concept and implications of competency-ba sed education. Educational Leadership. 1978: 16-22.

[4] Lee EC, Watson DR, Argo JK, Kalish RA, Catlin PC.A model for competency-based computer-managed instruction in allied health. J Allied Health. 1982:107-114.

[5] Bridges PH. Revalidation of competencies [master's thesis]. Atlanta, GA: Emory University; 1985.

[6] Aston-McCrimmon E. Analysis of the ratings of competency used in physical therapy practice. Phys Ther. 1986; 66: 954-960.

[7] Zimbelman J, Juraschek S, Zhang X, Lin V. Physical therapy workforce in the United States: forecasting nationwide shortages. The American Academy of Physical Medicine and Rehabilitation.2010; 2: 1021-1029.

[8] APTA. Vision 2020.American Physical Therapy Association. September 18, 2012. http://www.apta.org/vision2020/. Accessed October 7, 2012.

[9] Roach KE, Frost JS, Francis NJ, Giles S, Nordrum JT, Delitto A. Validation of the revised Physical Therapist Clinical Performance Instrument (PT CPI): Version 2006. Phys Ther. 2012; 92:416-428.

[10] [Kuehn B. Groups promote "key competencies" in training for premed and medical students. JAMA.2009;302:729.

[11] Richards JC, Rodgers TS. Approaches and methods in language teaching.2nd Ed. New York, NY: Cambridge University Press; 2001:141

[12] Bloom BS, Hastings JT, Madaus GF. Handbook on Formative and Summative Evaluation of Student Learning. New York, NY: McGraw-Hill Book Company; 1971.

[13] McKenna V, Connolly C, Hodgins M. Usefulness of a competency-based reflective portfolio for student learning on a master's health promotion programme. Health Educ J. 2010;70:170-175.
[14] Tindal G, Haladyna TM. Large-scale assessment programs for all students: Validity, technical adequacy \& implementati on. Mahwah, NJ: Lawrence Erlbaum Associates; 2002.

[15] Childs J, Whitman J, Pugia M, Sizer P, Flynn T, Delittle A. Knowledge in managing musculoskeletal conditions and educational preparation of physical therapists in the uniformed services. Military Medicine.2007; 172: 440-445.

[16] Cross V, Hicks C, Barnwell F. Comparing the importance of clinical competence criteria across specialties. Physiotherapy.2001; 87: 351-67.

[17] Kigin C. A systems view of physical therapy care: shifting to a new paradigm for the profession. PhysTher. 2009; 89:1117-1119.

[18] Dillman, D. Mail and internet surveys: The tailored design method. Hoboken, NewJersey: John Wiley \& Sons Inc.; 2006.

[19] APTA. Physical therapist (PT) careers overview. March 28, 2013. http://www.apta.org/PTCareers/Overview/. Accessed April 4, 2013.

[20] APTA. Today's physical therapist. January 2011. http://www.moveforwardpt.com/ForHealthCareProfessionals .aspx. Accessed April 4, 2013.

[21] APTA. The role of physical therapy in safe patient handling. August 22, 2012. http://www.apta.org/uploadedFiles/APTA org/About Us/Policies/HOD/Practice/RoleOfPhysTherSafeP atientHandlingHODP06-12-21-20.pdf\#search=\%22patient $\%$ 20safety\%22. Accessed November 3, 2012.

[22] Ford RC, Bachsa SA, Fotter MD, Methods measuring patients' satisfaction in health care organization. Health care management review.1997; 22 (2).

[23] May BJ. Teaching: a skill in clinical practice. Phys Ther. 1983; 63:1627-1633.

[24] Davis C Patient Interaction. 4thed.Thorofare, NJ: Slack Incorporated; 2006.

[25] Englander R, Cameron, T Ballard AJ, Dodge J, Bull J Aschenbrener CA. Toward a common taxonomy of competency domains for health professions and competencies for physicians. Acad Med.2013;88,081-7.

[26] Beattie BF, Pinto MB, Nelson NK, Nelson R. Patient satisfaction with outpatient physical therapy: instrument validation. PhysTher. 2002; 82(6): 557-565.

[27] Beattie P, Dowda M, Turner C, Michener L, Nelson R. Longitudinal continuity of care is associated with high patient satisfaction with physical therapy. Phys Ther. 2005; 85: 1046-1052.

[28] Schafer D, Lopopolo R, Luedtke-Hoffman K. Administration and management skills needed by physical therapist graduates in 2010: a national survey. Phys Ther. 2007; 87: 261-281.

[29] Salas E, Wilson K, Murphy C et al. Communicating, coordinating, cooperating when lives depend on it: tips for teamwork. JtComm J Qual Patient Saf. 2008; 34 (6): $333-341$

[30] Pronovost PJ, Berenholtz SM, Goeschel C, et al. Improving patient safety in intensive care units in Michigan. J Crit Care. 
2008; 23(2):207-221.

[31] Rabol LI, Ostergaard D, Mogensen T. Outcomes of classroom-based team training interventions for multi-professional hospital staff: A systematic review.QualSaf Health Care. 2010; 19(6):469-596.

[32] Baker S, Marshak H, Rice G, Zimmerman G. Patient participation in physical therapy goal setting. PhysTher.2001; 81:1118-1126.

[33] Lopopolo RB, Schafer DS and Nosse LJ.Leadership, Administration, Management, and Professionalism (LAMP) in Physical Therapy: A Delphi Study. Phys Ther. 2004; 84:137-15.

[34] Schafer D, Lopopolo R, Luedtke-Hoffman K. Administration and management skills needed by physical therapist graduates in 2010: a national survey. Phys Ther. 2007; 87: 261-281.

[35] Blau R, Bolus S, Carolan T, Kramer D, Mahoney E, Jette D, and Beal J. The experience of providing physical therapy in a changing health care environment.Phys Ther. 2002; 82:648-657.

[36] Schreiber J, Stern P. A review of the literature on evidence-based practice in physical therapy. The Internet Journal of Allied Health Sciences and Practice.2005; 3(4).

[37] Slavin MD. Teaching evidence-based practice in physical therapy: Critical competencies and necessary conditions. J Phys Ther Educ. 2004; 18(3): 4-11.

[38] Maher C, Sherrington C, Elkins M, Herbert R, Moseley A. Challenges for Evidence-Based Physical Therapy: Accessing and Interpreting High-Quality Evidence on Therapy. Phys Ther. 2004; 84: 644-654.

[39] Green ML, Ellis PJ. Impact of an evidence-based medicine curriculum based on adult learning theory. JGIM.1997; 12: $742-750$.

[40] Suter E, Arndt J, Arthur N, Parboosingh J, Taylor E, and Deutschlander S. Role understanding and effective communication as core competencies for collaborative practice. Journal of Interprofessional Care. 2009; 23(1): 41-51.

[41] Dean E, Al-Obaidi S, De Andrade AD et al. The first physical therapy summit on global health: implications and recommendations for the $21 \mathrm{st}$ century. Physiotherapy Theory and Practice. 2011; 27 (8): 531-547. 